IdeAs

Idées d'Amériques

$10 \mid 2017$

États-Unis / Cuba : une nouvelle donne?

Distribuir con la izquierda, castigar con la derecha. Las paradojas del punitivismo en la Venezuela posneoliberal

Andrés Antillano

2 OpenEdition

Journals

Edición electrónica

URL: https://journals.openedition.org/ideas/2208

DOI: 10.4000/ideas.2208

ISSN: 1950-5701

Editor

Institut des Amériques

Referencia electrónica

Andrés Antillano, «Distribuir con la izquierda, castigar con la derecha. Las paradojas del punitivismo en la Venezuela posneoliberal», IdeAs [En línea], 10 | 2017, Publicado el 19 diciembre 2017, consultado el 20 octubre 2022. URL: http://journals.openedition.org/ideas/2208 ; DOI: https://doi.org/10.4000/ ideas.2208

Este documento fue generado automáticamente el 20 octubre 2022.

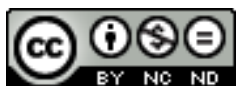

Creative Commons - Atribución-NoComercial-SinDerivadas 4.0 Internacional - CC BY-NC-ND 4.0 https://creativecommons.org/licenses/by-nc-nd/4.0/ 


\title{
Distribuir con la izquierda, castigar con la derecha. Las paradojas del punitivismo en la Venezuela posneoliberal
}

\author{
Andrés Antillano
}

\section{NOTA DEL AUTOR}

Para una versión extensa de este texto, ver Antillano, A., «Incluir y castigar: Tensiones y paradojas de las políticas hacia los pobres en la Venezuela pos-neoliberal» in Tavares dos Santos, J. y C. Barreria (Edits), Paradoxos da segurança cidadã. Editorial Tomo, Porto Alegre, 2016, p. 123-138.

¿Cuáles han sido las respuestas penales del gobierno bolivariano? ¿Existe alguna relación entre la naturaleza de un proyecto político y el uso del castigo? En este trabajo nos proponemos aproximarnos a la naturaleza y mutaciones tanto del discurso como de las políticas punitivas del chavismo. Durante estos 15 años, el gobierno bolivariano se ha desplazado desde una lectura «estructural» del delito y una recusación a las estrategias represivas del pasado a una interpretación «moral», que explica el delito como consecuencia de la persistencia de los valores del capitalismo, lo que ha ido de la mano con un aumento del castigo hacia los sectores empobrecidos.

\section{La retórica chavista de la seguridad}

2 Aunque la seguridad ha ocupado una posición periférica en la retórica y preocupaciones del chavismo, en el tratamiento del tema durante los primeros años del gobierno prevaleció una perspectiva «estructural» que asocia el aumento de la criminalidad con la pobreza, la desigualdad y la injusticia social. Los problemas del 
delito no se solucionarán sin antes superar las grandes taras sociales heredadas de los gobiernos neoliberales, se insiste. Esta perspectiva, que apunta a las raíces estructurales del delito, prevé como recurso principal para reducir la criminalidad el impulso de políticas sociales incluyentes y de medidas dirigidas a transformar las condiciones que producen la pobreza (Antillano A., 2012). Esta primera retórica que iguala sin cortapisa delito y pobreza, delincuencia e injusticia social, puede ser descrita como funcionalismo de izquierda, en tanto pretende una relación causal y mecánica entre condiciones sociales y estructurales y el delito.

3 Un segundo tópico recurrente durante estos primeros años, es el repudio a las prácticas represivas de los gobiernos anteriores y el reclamo de políticas de seguridad respetuosas de los derechos humanos y de las garantías individuales. Se prohíben las detenciones salvo por flagrancia $u$ orden judicial, se suprime el reclutamiento forzoso y las habituales redadas policiales en barrios pobres, entre otras decisiones que representan la voluntad de romper con aquellas políticas que implicaban la intensificación de la violencia estatal sobre los grupos sociales relegados. En esa misma línea, la Constitución aprobada en 1999 contará con un marcado talante garantista.

Estos discursos, sin embargo, conocerán durante los últimos años un desplazamiento que terminará acercando sus perspectivas sobre el delito y el castigo a las narrativas punitivistas que en un principio se recusaron. Por un lado, el tema de la inseguridad se vuelve cada vez más central, dejando atrás el lugar marginal que tenía en el proyecto bolivariano y en la preocupación de sus voceros. Desde 2009, cuando Chávez le dedica buena parte de su discurso de Memoria y Cuenta en el Parlamento al tema, la seguridad ha crecido en relevancia y presencia en la narrativa del chavismo, hasta convertirse en la principal oferta electoral de Nicolás Maduro, sucesor de Chávez luego de su fallecimiento.

Por otra parte, los argumentos que asocian la criminalidad con las injusticias sociales son dejados de lado, cediendo su lugar a explicaciones «morales» y causas individuales: el crimen es consecuencia de los valores morales propios del capitalismo que perviven en los delincuentes. Se sustituyen las causas estructurales por causas culturales (individualismo, egoísmo, competencia, consumismo). El criminal ya no se entiende como "víctima del capitalismo», sino como su expresión más acabada, el portador de sus valores, y en tanto tal no requiere de indulgencia, no es suficiente con los esfuerzos para superar la pobreza, sino que se demanda severidad y castigo. La lógica de la responsabilidad individual del delincuente, tan cara para los discursos neoliberales y punitivistas, reaparece de la mano de la vieja figura del lumpen. Curiosamente, los discursos del chavismo y de la oposición se acercan: el delito no responde a causas estructurales sino que se concibe como correlato del descalabro de determinados valores o de la inoculación de otros que conducen al crimen y la violencia.

\section{Desde las políticas «humanistas» a la mano dura}

Este cambio en el discurso tiene su paralelo en un desplazamiento en las prácticas institucionales. Tanto en el campo legislativo como en las políticas implementadas, es visible un endurecimiento de la postura gubernamental que coincide con la nueva retórica. 
7 En los primeros años, se verifica una disminución significativa de las respuestas punitivas. La población en prisión disminuye de 25000 reclusos en 1998, a cerca de 12000 en 1999, y los índices más notorios de abuso policial, como las detenciones masivas e ilegales, la represión a manifestaciones o las torturas, conocen un importante retroceso (PROVEA, 1998, 1999, 2000, 2001 y 2002). Paradójicamente, repuntan de manera abrupta otras formas más deletéreas de violencia policial, como las ejecuciones extrajudiciales. Incluso se reporta la presencia de escuadrones de la muerte que operan en varios estados del país (COFAVIC, 2005). Las restricciones al castigo formal y a prácticas policiales que se asociaban con patrones de abuso de su poder legal, como la prohibición de arrestos discrecionales, parecen haber contribuido al desplazamiento hacia prácticas informales, como el uso de castigos ilegales contra sujetos refractarios y grupos estigmatizados (Antillano A., 2010; Monsalve Y., 2005, 2006).

Durante los años siguientes y hasta la actualidad, opera un deslizamiento hacia políticas duras de castigo penal que implican el incremento de la violencia policial y de la población en prisiones. Estas políticas se distinguen poco de las fórmulas punitivistas promovidas por el neoliberalismo y de los dispositivos penales y policiales utilizados por los gobiernos anteriores, repudiados en el discurso chavista de los primeros tiempos. Entre los principales signos de este endurecimiento estarían las reformas legales que reducen garantías y amplían el uso de la prisión, el incremento de los tipos penales y el aumento de la severidad del castigo, en el plano legislativo; la utilización profusa de figuras que abrevian el proceso, debilitando las garantías procesales, promoviendo por vía coercitiva la autoinculpación y eliminando de facto el juicio contradictorio y el debido proceso, y el envío masivo de sospechosos a la prisión preventiva, en la administración de justicia; dispositivos policiales sobrerreactivos que se focalizan en la pequeña criminalidad callejera y aumentan la criminalización de grupos sociales desfavorecidos, en especial jóvenes de sectores populares urbanos, así como la creciente participación de fuerzas militares en labores de seguridad, en el orden de la actividad policial.

El gobierno bolivariano se inaugura con la puesta en vigencia de un nuevo código procesal, aprobado por la legislatura anterior, que, siguiendo el modelo de otras reformas en el continente, combina un enfoque garantista con medidas de orden managerial en el intento de desbloquear el colapso de la administración de justicia penal y generar un clima de certidumbre jurídica en un momento de apertura a la globalización. Al igual que en el resto de países de la región, el nuevo código conoció tempranas reformas que revirtieron sus aspectos más avanzados, como el juicio en libertad, las principales garantías procesales y las fórmulas alternativas de cumplimiento, a la vez que se fortalecen mecanismos expeditos de juzgamiento. Este nuevo proceso penal contribuyó significativamente en sus inicios con la reducción de la población en prisiones, llegando a las cotas más bajas desde los años 80 , cuando el ascenso de gobiernos de corte neoliberal fue acompañado por un aumento exponencial del número de personas enviadas a la prisión, y supuso la inversión de la condición jurídica dentro de las prisiones, de modo que por primera vez el volumen de condenados era mayor que la población procesada. En cambio, las reformas siguientes con su extensión del uso de la prisión preventiva, el encarecimiento de las fórmulas alternativas y la flexibilización de las formas de juzgamiento- disparan la población penal, que asciende rápidamente, y al ritmo de cada cambio legislativo, de 12000 a 20000 entre 1999 y 2010. 
10 Adicionalmente operan reformas penales que implican un aumento de las penas y de la severidad de su cumplimiento por la vía de reducción de beneficios y fórmulas alternativas. Reformas en el código penal y en las leyes antidrogas han endurecido significativamente el castigo de delitos propios de los pobres, a la vez que tanto modificaciones legislativas o jurisprudenciales, como una curiosa sentencia del Tribunal Supremo que considera los delitos de drogas como crímenes de lesa humanidad, y por lo tanto imprescriptibles y no elegibles para beneficios procesales y penales, hacen más severo el castigo, incrementando la duración de las penas o dificultando el otorgamiento de medidas de libertad anticipada y fórmulas alternativas.

En el orden policial, se reinstalan como prácticas dominantes las tácticas duras de policiamiento, orientadas a detenciones masivas de sujetos considerados peligrosos (jóvenes varones pobres) y a una hiperactivación frente a la pequeña criminalidad callejera: menudeo de drogas, hurtos y pequeños robos, etc. Esta sobrerrepresentación de la criminalidad callejera en las detenciones de la policía conduce a la saturación del sistema penal por casos de flagrancia que, de acuerdo a datos preliminares de un estudio que realizamos en tribunales de Caracas, ocupa más del 90 por ciento de las causas que se procesan (Antillano A. et al., 2012; Reyna de Roche C. L. y J. Richter., 2007, para una descripción del funcionamiento del proceso penal venezolano). Sobre todo a partir de 2009, hay un creciente protagonismo de fuerzas militares en labores policiales, tanto en patrullaje como en tareas de coordinación y comandos de cuerpos civiles (Antillano A., 2014). La intensidad de la respuesta policial habría contribuido con nuevos incrementos en la población encarcelada, que asciende a partir de 2009 por encima de los 50000 reclusos.

Desde 2014, la violencia policial crece de manera exponencial, superando en 2016 las 4000 víctimas muertas en operativos policiales. Estas actuaciones se ceban en los sectores menos favorecidos (jóvenes pobres de barrios periféricos) que tradicionalmente habían contado con un lugar favorecido en el ideario justiciero del chavismo. Paradójicamente, a pesar de la dureza y letalidad de las intervenciones, la violencia criminal, lejos de disminuir, se incrementa (Antillano A. y Ávila K., 2017).

\section{Entre la inclusión y el castigo: el gobierno de los pobres en Venezuela}

13 ¿Cómo comprender estas oscilaciones y mudanzas? ¿Qué explica esta primacía de políticas duras que finalmente criminalizan a los sectores populares, sujeto privilegiado del proyecto chavista?

Habría que entender las políticas punitivas en su relación con las otras estrategias dirigidas hacia los pobres, como propone Wacquant para el caso norteamericano (Wacquant L., 2010). Políticas sociales y políticas penales son dos caras de una misma moneda, constituyen un complejo entramado en el gobierno de las clases populares. Para el caso de Venezuela, las políticas hacia los pobres operarían en una suerte de bifurcación que oscilaría entre las estrategias de inclusión social y las estrategias de control penal, que terminan complementándose.

15 Es indudable el esfuerzo realizado durante este periodo para la reducción de la pobreza y la inclusión de grupos relegados, a través de políticas de protección social (como la ampliación de la cobertura de la seguridad social y de las pensiones, la reforma laboral 
de 2012, la protección del empleo), políticas redistributivas y de acceso a bienes y servicios para los sectores populares (redes de salud, de distribución de alimentos, acceso a la educación, a los servicios básicos, etc.), y políticas sociales focalizadas (misiones sociales, subsidios, prestaciones económicas de diverso orden), redundando en la disminución de la desigualdad (que se redujo de 0,48 a 0,38 de acuerdo al índice Gini), la pobreza (que conoce un descenso de 55\% a 28\%), la mortalidad infantil (la tasa de natalidad pasó de 72 a 77 nacimientos vivos por cien mil), entre otros indicadores. Aún cuando en estos últimos años el empuje de estas políticas de inclusión parece haber perdido algo de fuerza, siguen siendo de una magnitud considerable y su impacto insoslayable.

16 Sin embargo, a la vuelta del tiempo estas estrategias no parecen capaces de revertir las condiciones estructurales que generan exclusión y desigualdad, más allá de su impacto en el mejoramiento de la situación social de las clases populares. Nuestra hipótesis es que en las sociedades pos-industriales (Harvey, 1989) y pos-salariales (Svampa M., 2004; Castel R., 2010), cuando el trabajo y la economía formal ya no garantizan la inclusión de las grandes mayorías, las políticas redistributivas pierden el efecto universal que pudieron tener dentro del Estado de Bienestar keynesiano o de propuestas de orden socialista. Esto se haría aún más evidente en economías rentistas como la venezolana. Así, las políticas sociales y redistributivas tendrían un alcance limitado en esta dirección, pero a la vez provocarían como efecto paradójico nuevas diferencias sociales entre aquellos que mejoran su grado de inclusión como resultado de las mismas, a partir del ingreso a la economía formal o el acceso a redes institucionales, y aquellos grupos que quedan relegados.

La distancia social entre los nuevos incluidos y los excluidos persistentes, entre quien ha encontrado un empleo estable o sus ingresos han mejorado como efecto de las políticas sociales y quien no ha logrado tales ventajas, se convierte en una fuente importante de conflicto y descontento, aun cuando ambos pertenezcan a la misma clase social, al mismo vecindario o incluso a un mismo grupo familiar. Junto a las desigualdades «jerárquicas», estructurales (Fitoussi J.P. y P. Rosanvallon., 1997) que describen diferencias de ingreso entre categorías sociales verticales, florecen nuevas desigualdades «horizontales», dinámicas, al interior de una misma categoría social antes homogénea. Estas desigualdades intraclase entre grupos atendidos y grupos relegados explicarían el desarrollo simultáneo y complementario de políticas de inclusión y políticas punitivas, en tanto que las segundas actuarían como un mecanismo de control de aquellos grupos y sujetos que no han sido incorporados o son refractarios a las estrategias de inclusión. Se alternarían políticas sociales, dirigidas a determinados grupos de las clases populares y políticas punitivas que actuarían sobre sectores residuales impermeables a sus efectos.

Esta bifurcación entre políticas sociales y políticas penales terminarían reforzando, e incluso instituyendo, las diferencias intraclase, al distinguir entre los clientes de las políticas sociales y los de las políticas de castigo. Incluidos y relegados, víctimas y victimarios, honestos y peligrosos: crimen, temor al delito y políticas penales trazan los contornos de las nuevas fronteras sociales que hacen emerger las políticas focalizadas de inclusión, en un orden donde ya el trabajo y el salario no definen los clivajes y las jerarquías. 


\section{BIBLIOGRAFÍA}

Antillano, Andrés, «Seguridad y política en la Venezuela bolivariana: la seguridad en el debate político venezolano entre 1998-2009», Espacio Abierto, vol. 21, n²4, Venezuela, 2012, p. 701-726.

Antillano, Andrés, «La reforma policial en la Venezuela bolivariana» in José Alfredo Zavaleta Betancourt (dir.), El laberinto de la inseguridad ciudadana: bandas criminales, seguridad de fronteras $y$ regímenes penitenciarios en América Latina, $1^{\text {a }}$ ed., Buenos Aires, CLACSO, 2014, p. 63-92.

Antillano, Andrés y Keymer Ávila, «¿La mano dura disminuye los homicidios? El caso de Venezuela», CIDOB d'Afers Internacionals, 116, 2017, p. 77-100.

Antillano, Andrés, Iván Pojomovsky, Alejandro Bastardo et al., «¿Qué hace el CICPC? Descripción de las actividades rutinarias de investigación de un grupo de detectives», in Gabaldón, L.G. (dir.), Diagnóstico y propuestas de reforma del Cuerpo de Investigaciones Científicas, Penales y Criminalísticas. Avances del nuevo modelo policial venezolano, Consejo General de Policía, 2012, p. 39-54.

Castel, Robert, El ascenso de las incertidumbres, Buenos Aires, FCE, 2010.

COFAVIC, Los Grupos Parapoliciales en Venezuela, Caracas, 2005.

Fitoussi Jean-Paul y Pierre Rosanvallon, La nueva era de las desigualdades. Buenos Aires, Manantial, 1997.

Harvey, David, The condition of postmodernity. Oxford, Blackwell, 1989.

Monsalve, Yoana, «Control social y castigo: Percepción en funcionarios policiales venezolanos». Capítulo Criminológico, n³3-1, Venezuela, Universidad de Zulia, 2005, p. 7-30.

Monsalve, Yoana, «Repercusiones del sistema de justicia en el castigo policial». Capítulo Criminológico, $\mathrm{n}^{\circ}$ 34-1, Venezuela, Universidad de Zulia, 2006,p. 5-32.

PROVEA, Situación de los Derechos Humanos en Venezuela. Informe Anual. Caracas, 1998.

PROVEA, Situación de los Derechos Humanos en Venezuela. Informe Anual. Caracas, 1999.

PROVEA, Situación de los Derechos Humanos en Venezuela. Informe Anual. Caracas,2000.

PROVEA, Situación de los Derechos Humanos en Venezuela. Informe Anual. Caracas,2001.

PROVEA, Situación de los Derechos Humanos en Venezuela. Informe Anual. Caracas, 2002.

Reyna de Roche, Carmen Luisa y Jacqueline Richter, Justicia penal y Defensa Pública, Caracas, FCJP, 2007.

Svampa, Maristella, «Cinco tesis sobre la nueva matriz popular» Lavboratorio. Revista de estudios del cambio social, VI, $n^{\circ} 15$, Buenos Aires, Instituto G.Germani, Fac. De Cs Sociales, Universidad de Buenos Aires, 2004.

Wacquant, Loïc , Castigar a los pobres, Barcelona, Gedisa, 2010.

\section{AUTOR}

\section{ANDRÉS ANTILLANO}

Andrés Antillano. Estudios en Psicología Social (Universidad Central de Venezuela) y Criminología (Universitat de Barcelona). Investigador del Instituto de Ciencias Penales y profesor 
de la UCV. Se ha desempeñado como miembro de la Comisión Nacional para la Reforma Policial (2006) y la Comisión Presidencial para el Desarme (2010). Activista social, se ha involucrado con luchas urbanas, organizaciones juveniles y territoriales, y defensa de derechos humanos de grupos vulnerables. Ha realizado publicaciones sobre políticas de seguridad, policía, prisiones, drogas y violencia. 